\title{
Hepatitis C virus to hepatocellular carcinoma
}

\author{
Shah Jahan ${ }^{1 *}$, Usman A Ashfaq ${ }^{2 *}$, Muhammad Qasim², Saba Khaliq ${ }^{1}$, Muhammad Javed Saleem ${ }^{3}$ and \\ Nadeem Afzal ${ }^{1}$
}

\begin{abstract}
Hepatitis $C$ virus causes acute and chronic hepatitis and can lead to permanent liver damage and hepatocellular carcinoma (HCC) in a significant number of patients via oxidative stress, insulin resistance (IR), fibrosis, liver cirrhosis and HCV induced steatosis. HCV induced steatosis and oxidative stress causes steato-hepatitis and these pathways lead to liver injury or HCC in chronic HCV infection. Steatosis and oxidative stress crosstalk play an important role in liver damage in HCV infection. This Review illustrates viral and host factors which induce Oxidative stress, steatosis and leads toward HCC. It also expresses Molecular cascade which leads oxidative stress and steatosis to HCC.
\end{abstract}

\section{Introduction}

Hepatitis $C$ virus causes acute and chronic hepatitis [1] an can leads to HCC via oxidative stress, insulin resistance (IR), fibrosis, liver cirrhosis and HCV induced steatosis [2]. HCV is a major health problem, almost 350 million individuals are chronically $\mathrm{HCV}$ infected [3] and $10 \%$ of the Pakistani population is chronically infected with this viral pathogen [4]. Approximately 40$60 \%$ of $\mathrm{HCV}$ infected individuals leads to chronic liver disease [5], and prevalence of HCV associated HCC is higher in Pakistan as compare to the rest of world [6,7].

$\mathrm{HCV}$ is an enveloped positive-single stranded RNA virus $9.6 \mathrm{~kb}$ in length consisting of (Core, E1, E2 and possibly p7) proteins and nonstructural (NS2, NS3, NS4A, NS4B, NS5A and NS5B) viral proteins $[8,9]$. $\mathrm{HCV}$ Core is known as the inducer of steatosis, oxidative stress and HCC [10]. E1 and E2 are involved in virus attachment with the cells and are considered to be the first viral protein comes in contact with the cells [11]. p7 is possibly concerned with ion channel and virus assembly [12]. HCV has six genotypes and 52 subtypes mainly genotypes in the different region of the world are (1a, b, c, 2a, b, c, 3a, b, 4a, 5a, 6a). Due to absence of proofreading function of the RNA-dependent RNA-polymerase (NS5B), HCV has a high mutation rate and exists as genetically heterogeneous quasispecies in

\footnotetext{
* Correspondence: captainmalik@hotmail.com; usmancemb@gmail.com ${ }^{1}$ Department of Immunology, University of Health Sciences, Lahore, Pakistan Department of Bioinformatics and Biotechnology, Government college university (GCU), Faislabad, Pakistan

Full list of author information is available at the end of the article
}

individual patients $[13,14]$. The genetic diversity is more than 30\% in different genotypes and 20\% in subtypes. Variations in amino acid sequence of different HCV genotypes cause difference in severity of pathogenesis. Recent studies have shown variable responses for interferon (IFN)-ribavirin combination therapy, oxidative stress/steatosis and insulin resistance due to the amino acid substitutions in the HCV Core region of different HCV genotypes.

HCV genotype $3 \mathrm{a}$ is mainly prevalent in Pakistan followed by $3 \mathrm{~b}$ and 1a [15]. Moreover, a strong correlation between chronic HCV infection and HCC in Pakistan associated with genotype $3 \mathrm{a}$ has been observed which is not been observed in relation to any other genotype [6]. $\mathrm{HCV}$ genotype 3a is mostly involved in $\mathrm{HCV}$ induced steatosis [16]. HCV induced steatosis and oxidative stress causes steatohepatitis [17] and these pathways leads to liver injury or HCC in chronic HCV infection $[10,18]$. Steatosis and oxidative stress crosstalk play important role in liver damage in HCV infection [19].

Oxidative stress is a key contributor in HCV-induced pathogenesis (Tardif et al., 2005). Previous reports showed that HCV Core protein regulates gene expression and alter cell signaling pathways [20] leading to oxidative stress, liver steatosis and eventually HCC [21]. HCV Core protein also up regulates cyclooxygenase-2 (COX-2) expression in hepatocytes and causes oxidative stress leading to HCC [22,23]. Cellular genes inducible nitric oxide synthetase (iNOS) COX-2 and Vascular Epidermal Growth Factor (VEGF) regulate cellular growth and over expression of these genes has carcinogenic 
effects in liver cells [24]. COX-2 can induce angiogenesis growth factors via VEGF [25-27] and it has also been revealed that the over expression of COX-2 activates Akt by phosphorylation of Akt in human HCC [28]. Akt acts as a key signal mediator, which modulates cell survival and proliferation [29,30]. Different studies have shown the effect of $\mathrm{HCV}$ on these genes but effect of HCV genes on these cellular genes which are crucial for HCV pathogenesis has not been evaluated completely.

Steatosis, the most common cause of abnormal liver function, is a pathological condition in which simple triglyceride accumulation in hepatocytes cause hepatic steatosis that leads to HCC and other liver diseases (Tetri and Caldwll, 2003). In fatty acid synthesis pathway loss of adiponectin Receptor (Adipo R2) due to $\mathrm{HCV}$ activates of the enzyme acetyl-CoA carboxylase (ACC) [31] a rate-limiting enzyme for fatty acid synthesis. ACC catalyzes synthesis of malonyl CoA that is further converted into saturated fatty acids by the action of fatty acid synthase (FAS) [32]. In addition, the transcription factors such as sterol regulatory element binding protein (SREBP) and peroxisomal proliferator activator receptor- $\alpha$ (PPAR- $\alpha$ ) are also the key player in both lipogenesis and fatty acid oxidation pathways. SREBP activates the entire gene involved in lipogenesis [33]. A major function of PPAR- $\alpha$ is to control fatty acid oxidation and activation and its deficiency results in defective fatty acid oxidation $[34,35]$. It has been demonstrated that HCV proteins may accumulate triglycerides in hepatocytes by modulating the fatty acid synthesis pathway which leads to steatosis [32]. However, the mechanism involved in the HCV induced steatosis is still not clear.

Apoptosis is fundamental process for the control and elimination of viral infections. The impact of apoptosis in chronic HCV infection is not well understood. It may be harmful by triggering liver fibrosis, or essential for viral elimination [36]. HCV proteins, particularly Core and NS5A protein have both pro- and anti-apoptotic effects. It is not known which HCV protein affects apoptosis and whether the infectious virions act pro- or antiapoptotic. E1 and E2 are involved in virus attachment with the cells [37].

\section{Oxidative stress}

Oxidative stress refers to the oxidation-reaction-dominant state of the living body induced by an imbalance between the oxidation reaction caused by reactive oxygen species (ROS) and the anti-oxidation reaction. Main ROS include superoxide (O2-), hydrogen peroxide $(\mathrm{H} 2 \mathrm{O} 2)$ and the hydroxyl radical $(\mathrm{HO})$ [17]. Oxidative stress has emerged as a key contributor in the development and progression of many pathological conditions, including $\mathrm{HCV}$-induced pathogenesis of liver [38]. Mainly in liver cells NO production which is induced by iNOS enzyme which is activated in inflammatory process.

\section{$\mathrm{HCV}$ induced oxidative stress}

Oxidative stress is produced by inflammatory progressions that occur in hepatitis via immunological mechanisms. In addition, in $\mathrm{HCV}$ infectious disease, viral proteins have some functions in the induction of oxidative stress. In $\mathrm{HCV}$ infection, ROS are produced by NADPH oxidize and xanthine oxidase in neutrophils and macrophages [39]. It have been also demonstrated that oxidative stress plays an important role in $\mathrm{CHC}$ [40]. In the presence of hepatic steatosis, IR and increased levels of some cytokines, all of which are also stimulated by viral protein expression, oxidative stress is enhanced in $\mathrm{HCV}$ infection. In addition, HCV produced ROS also in hepatocytes in response to release of inflammatory cytokine from inflammatory cells $[18,41]$. A pathological relationship between oxidative stress and $\mathrm{HCV}$ infection is observed, the causes of oxidative stress in HCV infection are considered to include various factors such as mitochondrial damage, lipid accumulation and ER stress in the liver. Different studies revealed that viral proteins, mainly the HCV Core protein, cause oxidative stress. In this sense, inflammation in $\mathrm{CHC}$ is considered to be qualitatively different from inflammation observed in other types of hepatitis such as autoimmune hepatitis or hepatitis [17].

\section{HCV structural genes and oxidative stress}

In addition to nucleocapsid formation, HCV Core protein also modulates gene transcription, cell proliferation, cell death, and cell signaling, interferes with lipid metabolism and suppresses host immune response [20]. Core is an important pathogenic determinant of $\mathrm{HCV}$ induced oxidative stress leading to liver steatosis, and HCC $[21,42]$. In addition, it is notable that in HCV infection the viral proteins themselves as well as inflammation due to hepatitis are regarded as a cause of oxidative stress [23]. HCV Core protein is known as the inducer of steatosis, oxidative stress and HCC [10]. $\mathrm{HCV}$ structural genes, particularly the Core protein, have different functions with respect to host cells [43] and are closely related to oxidative stress. Core protein is also able to up regulate ROS production by induced nitric oxide Synthetase (iNOS) which activates cyclooxygenase-2 (COX-2) expression in hepatocytes derived cells, providing a potential mechanism for oxidative stress leading to HCC $[22,23]$. The Core protein was found to have a variety of actions, including the induction of oxidative stress and accumulation of lipids, in cultured cells and transgenic mice $[10,23]$ and an 
enhanced ROS production caused by damage of the mitochondrial electron transport system was observed in Core-protein-expressing cells [23]. Mitochondrial DNA, which has no protective proteins such as histone, is susceptible to damage by ROS in response to HCV and causes Apoptosis [44,45] and could also increase oxidative stress caused by damage of the electron transport system. Core is an important pathogenic determinant of $\mathrm{HCV}$ induced oxidative stress. It is also able to up regulate COX-2 expression in hepatocyte derived cells, providing a potential mechanism for hepatic fibrosis during chronic HCV infection [23].

\section{Cellular genes involved in HCV induced oxidative stress and $\mathrm{HCC}$ \\ iNOS}

In an inflammation, iNOS is induced in macrophages and hepatocytes [46,47]. iNOS is related to a high-output pathway of oxidative stress and is responsible for various pathological processes [25]. In fact, iNOS synthesis correlates with intra hepatic viral load in CHC [48]. $\mathrm{NO}$ causes cellular damage upon its reaction to $\mathrm{O} 2$ and finally produced nitro tyrosine, which was observed in association to inflammation severity in $\mathrm{CHC}$ tissue [49] suggesting that the production of both NO and ROS increased. ROS and RNS are produced as defense factors against viral infection, but these. ROS and RNS also have cytotoxic effects. Over production of iNOS and COX-2 have carcinogenic effects achieved either directly or by producing mediator that regulate cellular growth [25-27]. Elevated NO production has been implicated as a cause of tissue damage by inflammation, thus contributing to liver tumor promotion [50]. NO has been shown to induce oxidative DNA damage and inhibit DNA repair [51]. The expression of both COX-2 and iNOS was significantly elevated in HCV-positive HCCs. These findings suggest that combined expression of iNOS and COX-2 may play an important role in the prognosis of HCV-positive HCC patients. Rahman et al. in 2001 examined COX-2 expression significantly correlated with iNOS expression playing an important role in prognosis of HCV-positive HCC patients that could be partially attributable to modulation of angiogenesis by COX-2 and a combined negative expression of iNOS and COX-2 had a significant impact on patient survival. COX-2

Two isoforms of COXs have been identified, COX-1 and COX-2, both catalyzing the same enzymatic reaction. Despite the structural similarity, COX-1 and COX-2 are regulated and function differently [52]. COX-2 is not constitutively expressed, but is rapidly induced by both inflammatory and mitogenic stimuli resulting in increased Prostaglandins (PG) synthesis in neoplastic and inflamed tissues. PGs play a central role in inflammation, and COX is the key enzyme in the conversion of arachidonic acid to prostaglandins. COX-2 is induced by a variety of factors such as ROS, cytokines, growth factors and tumor promoters and has been connected to inflammation and the inhibition of apoptosis leading to carcinogenesis $[53,54]$. The expression of COX-2 in HCC was found to correlate with the levels of several key molecules implicated in carcinogenesis such as iNOS activate VEGF and p-Akt $[55,56]$. iNOS and COX-2 have carcinogenic effects achieved either directly or by producing mediator that regulate cellular growth [24]. COX-2 can induce angiogenesis growth factors via VEGF [25-27].

Upregulation of COX-2 has been detected in HCC $[25,55,57]$. COX-2 have carcinogenic effects $[58,59]$ achieved either directly or by producing mediators that regulate cellular growth. COX-2 can induce angiogenesis via VEGF and PG production [25-27] and can also inhibit apoptosis by inducing the antiapoptotic factor Bcl-2 as well as activating antiapoptotic signaling through Akt/PKB. Phospho-Akt-Ser473 is also upregulated and causes the activation of COX-2 expression in liver cells. COX-2 plays an important role in VEGF-induced angiogenesis via p38 and JNK kinase activation pathways as VEGF-induced cell proliferation was significantly reduced when transfected with COX-2 siRNA (34.12 \pm $5.81 \%$ ) [60]. COX-2 expression in Huh-7 cell line was inhibited by selective COX-2 inhibitor (SC-58635) or COX-2 siRNA and dramatically suppressed the proliferation, migration, and differentiation in vitro and in vivo. An approximately 78\% reduction of VEGF level has been found in COX-2 siRNA treated Huh-7 confirmed the role of COX-2 in induction of VEGF. Moreover, COX-2/PGE $/$ /EP/VEGF pathway possibly also contributes to tumor angiogenesis in HCC [61]. COX-2specific siRNAs were electroporated into SNU-387 cells and significant, sequence specific reductions in COX-2 expression, PGE2 production, and cell proliferation were observed (Park et al., 2006). Recent evidence indicates that COX-2 modulates angiogenesis either by augmenting the release of angiogenic peptides by tumor cells or by directly increasing the production of PGs $[24,62]$.

\section{PGE 2}

PGs play a central role in inflammation, and COX is the key enzyme in the conversion of arachidonic acid to PG. The first step in the formation of PG is the liberation of arachidonic acid (AA) from membrane-bound phospholipids COXs $[63,64]$. It appears that inflammationmediated induction of COX-2 may represent a pivotal step in hepatocarcinogenesis. Recent experimental evidence suggests that increased COX-2 expression and PG production may contribute to the development of HCC. Several recent studies indicate that the COX-2/ PGE2 pathway is involved in HCC cell invasion $[65,66]$. 
Leng et al. in 2003 showed that COX-2 and PGE2 promote the growth of human HCC cells. In cultured HCC cells, over expression of COX-2 or treatment with PGE2 enhances VEGF production and this effect is blocked by inhibition of COX-2 [26]. Transfection of human HCC cell lines Hep3B and HepG2 with COX-2 expression vector or treatment with exogenous PGE2 induced phosphorylation of serine/threonine protein kinase $\mathrm{B}$ (Akt) and enhanced cell growth [28]. The observations that celecoxib inhibits the production of PGE2 in HCC cells and that COX-2 or PGE2 partial protects against celecoxib-induced apoptosis suggest the involvement of COX-2 inhibition in celecoxib-induced inhibition of HCC cell growth [28]. Therefore, in addition to hepatocarcinogenesis, COX-2-controlled PGE2 production signaling may also contribute to the pathogenesis of chronic hepatitis and cirrhosis.

\section{p Akt}

The expression of COX-2 in HCCs was found to correlate with the levels of several key molecules implicated in carcinogenesis, such as p-Akt [28], VEGF [26,27] and iNOS [25,28]. Leng et al (2003) showed a positive correlation between the expression of COX-2 and phosphorylated Akt/Protein kinase B (PKB) in human HCC, suggesting a potential role of Akt in COX-2-mediated hepatocarcinogenesis. The level of COX- 2 expression and Akt phosphorylation is positively correlated in cultured HCC cells and in human liver cancer tissues. Furthermore, inhibition of Akt activation by phosphatidylinositol 3-kinase (PI3-kinase) inhibitor LY294002 significantly decreased the viability of HCC cells [28]. These findings suggest an important role of Akt activation in COX-2-induced HCC cell survival. The observations that celecoxib treatment decreased the phosphorylation of Akt and that inhibition of Akt reduced HCC cell viability suggest that involvement of pAkt in HCC $[28,30]$.

VEGF

Vascular Epidermal Growth Factor synthesis occurs via oxidative stress and calcium signaling induced by $\mathrm{HCV}$ gene expression. VEGF the most potent angiogenic factor for tumor angiogenesis is believed to be involved in COX-2-mediated angiogenesis [58,59]. COX-2 can induce angiogenesis via VEGF and PG production. Moreover, COX-2/PGE $/ 2$ EP/VEGF pathway possibly also contributes to tumor angiogenesis in HCC (Zhao et al., 2007). There is also compelling evidence suggesting an important role of angiogenesis in COX-2-mediated hepatocarcinogenesis. COX-2 has been shown to induce angiogenesis via VEGF $[62,67]$. Two recent studies show that elevated COX-2 expression correlates with increased VEGF level and micro vascular density in human HCCs [26,27]. There is also evidence that the COX-2 inhibitor reduces the production of VEGF, a potent stimulator of angiogenesis in Huh-7 cells [26].

\section{Mechanism of oxidative stress leading to HCC}

Oxidative stress has emerged as a key contributor in the development and progression of many pathological conditions, including $\mathrm{HCV}$-induced pathogenesis of liver (Tardif et al., 2005). The expression of COX-2 in HCC was found to correlate with the levels of several key molecules implicated in carcinogenesis such as iNOS, VEGF and p-Akt [25,55]. COX-2 and iNOS have carcinogenic effects achieved either directly or by producing mediator that regulate cellular growth [24]. COX-2 can induce angiogenesis growth factors via VEGF (Rahman et al., 2001; Cheng et al., 2004; Tang et al., 2005). VEGF is also stimulated by a number of other inflammatory mediators including $\mathrm{NO}$ and certain cytokines. Previously, it has been shown that the over expression of COX-2 activates Akt in human HCC via a p13kinase-dependent mechanism [28]. Akt acts as an important signal mediator, which regulates cell survival and proliferation $[29,30]$. High nitric oxide production has been concerned as a cause of tissue damage by inflammation, thus contributing to liver tumor promotion [50]. The expression of both COX-2 and iNOS was significantly elevated in HCV-positive HCCs; the level of COX-2 expression was significantly correlated with iNOS expression [25]. These findings suggest that combined expression of iNOS and COX-2 may play an important role in the prognosis of $\mathrm{HCV}$-positive $\mathrm{HCC}$ patients. A few studies have revealed that COX-2 expression is correlated with VEGF expression in HCC [25-27]. COX-2/PGE 2 /EP/VEGF pathway possibly also contributes to tumor angiogenesis in HCC (Zhao et al., 2007). Expression of HCV sub genomic replicons or replicon RNA in human $\mathrm{HCC}$ cells increases COX-2 expression at the level of transcription through HCVinduced oxidative stress and subsequent activation of NF-kB (Cheng et al., 2004). The positive correlation between COX-2 and VEGF in the noncancerous liver tissues (Tang et al., 2005) suggests that COX-2 may also be involved in the angiogenesis in chronic liver disease through the VEGF pathway.

\section{HCV induced oxidative stress and steatosis lead to HCC}

Oxidative stress and steatosis is supposed to play a pivotal role in the development of liver injury or HCC in chronic HCV infection (Figure 1) [10,18]. It has been reported that $\mathrm{HCV}$ genotype $3 \mathrm{a}$ is mostly involved in oxidative stress and HCV induced steatosis [16], which both contributes in the development of HCC $[21,42,68]$. Studies have shown the occurrence of oxidation stress and lipid peroxidation in $\mathrm{CHC}$ patients leads to $\mathrm{HCC}$ [69]. HCC is one of the most common causes of malignancy-related death in Africa and Asia (Koga, 2003). The role of oxidative stress in the progression of chronic hepatitis and hepatocarcinogenesis is greater in hepatitis 


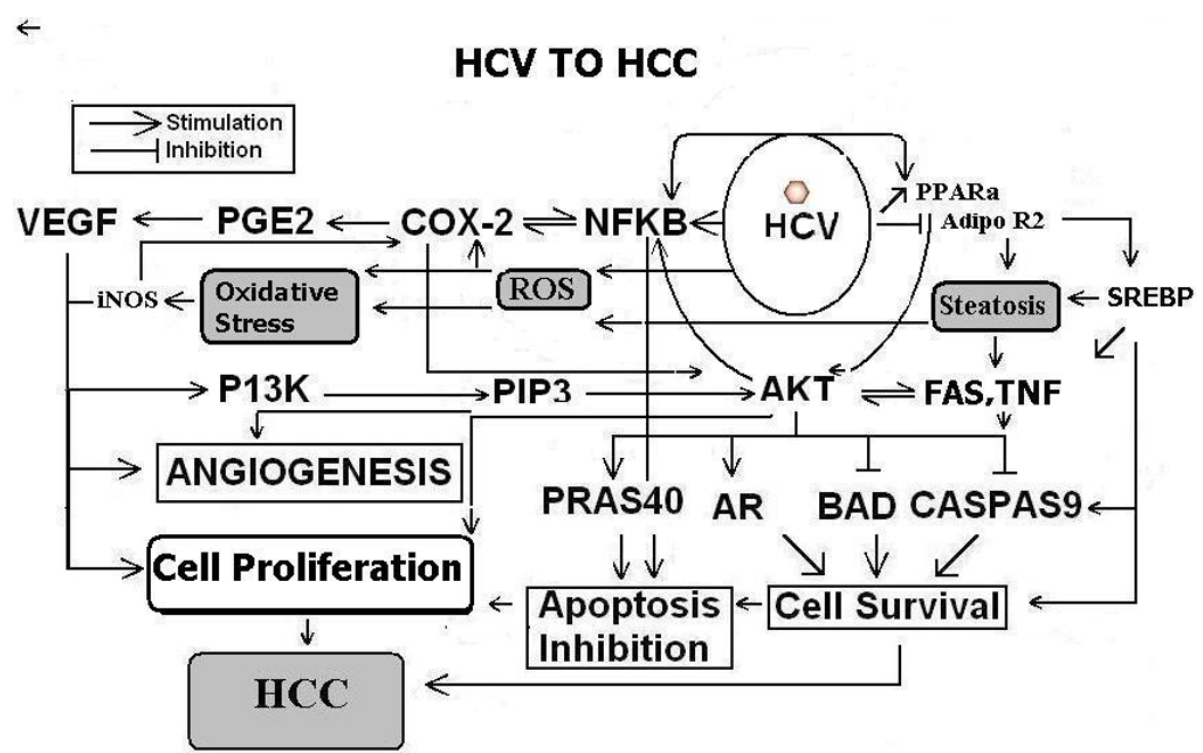

Figure 1 Schematic representation of HCV to HCC.

C than in other types of hepatitis such as hepatitis B or autoimmune hepatitis. The additive effects of oxidative stress caused by the inflammatory process and that induced by $\mathrm{HCV}$ proteins may, furthermore, exert synergistic effects with alterations in intracellular signaling systems such as MAPK, which are also induced by HCV proteins. These synergistic effects may be responsible for rare characteristics, that is, the high incidence and multicentric nature of hepatocarcinogenesis in $\mathrm{HCV}$ infection. According to other proposed mechanism $\mathrm{HCV}$ Core and NS proteins may accumulate ROS which results in the peroxidation of membrane lipids and structural proteins, which are involved in the trafficking and secretion apparatuses, which block the VLDL secretion and causes mitochondrial dysfunction, DNA and cellular protein damage and further aggravate oxidative stress [42]. ROS production causes kupffer cells bursting which results in release of cytokines: TNF $\alpha$, IL6 and IL8 [15]. TNF $\alpha$ down regulate the adiponectine thus, inducing IR and steatosis.

In human HCV genotype 3, which is most common in Pakistan, is more commonly associated with steatosis [70]. HCV induced Steatosis and oxidative stress is the most frequent cause of abnormal liver function. The Core protein was found to have a variety of actions, including the induction of oxidative stress and accumulation of lipids, in cultured cells and transgenic mice $[10,23]$. An increased ROS production and increased levels of intrahepatic peroxide lipids was observed in the Core gene transgenic mice as compare to control mice also show increased oxidative stress. Increased ROS production has been reported due to $ß$-oxidation in the mitochondria and peroxisomes or the metabolism of fatty acids by cytochrome P450 2E1 (CYP2E1) in microsomes is promoted under an excessive load of fatty acids (Day and James. 1998: Weltman et al., 1998). In $\mathrm{HCV}$ infection intrahepatic fat accumulation possibly increases ROS production as in $\mathrm{HCV}$ induced steatosis. Because hepatic steatosis in chronic hepatitis $C$ was reported to be a cause for disease development (Czaja et al., 1998) increased oxidative stress related with hepatic steatosis is most probably involved in disease progression. Oxidative stress markers, 8-Hydroxy deoxyguanosine (8-OHdG) and peroxylipids were found to be decreased in PPAR $-\alpha$ KO Core gene transgenic mice which contributes to increased production of oxidative stress [10]. HCV Core protein down regulates the adiponectine receptor which further down regulates PPAR and up regulates $\mathrm{JNK}, \mathrm{AP}-1$ and cyclin D1 which results in, activation of cell growth signaling leads to HCC. On the other hand down regulation of adiponectine receptor also activates hepatic cells HSC due to which net collagen synthesis increases which lead to fibrosis and HCC.

\section{$\mathrm{HCV}$ and disease progression}

$\mathrm{HCV}$ can leads to IR, fibrosis, liver cirrhosis and steatosis in a substantial number of patients [71-73]. Some studies showed that steatosis is more associated with fibrosis progression in $\mathrm{HCV}$ patients infected with genotype 3 i.e. patients with viral induced steatosis [74,75]. Other studies showed that metabolic steatosis is significantly associated with more sever fibrosis [76,77]. High level of TNF- $\alpha$ in CHC patient has been shown to 
induce IR in cultural cells and animal models [78,79]. Several studies reveal that IR is associated with nonalcoholic steatohepoatitis (NASH) and is also associated with a high risk of HCC that means IR increases the risk of chronic liver diseases and HCC. Moriya and colleagues showed that transgenic expression of Core protein leads to extensive steatosis, increased oxidative stress, mitochondrial injury and $\mathrm{HCC}$ in aging mice [21]. HCV induced steatosis and oxidative stress causes steatohepatitis [17] and these pathways leads to liver injury or HCC in chronic HCV infection $[10,18]$. Steatosis and oxidative stress crosstalk play important role in liver damage in $\mathrm{HCV}$ infection.

\section{Conclusion}

The review describes viral and host factors which induce Oxidative stress, steatosis and leads toward HCC. Molecular cascade that leads to oxidative stress and steatosis to HCC has also been illustrated. In future, these biomarkers and therapeutic tartget can be used in the treatment of hepatocellular carcinoma.

\section{List of abbreviations}

HCV, HCC, Oxidative stress, Steatosis, HCV pathogenesis Core, HCC

\author{
Author details \\ 'Department of Immunology, University of Health Sciences, Lahore, Pakistan. \\ ${ }^{2}$ Department of Bioinformatics and Biotechnology, Government college \\ university (GCU), Faislabad, Pakistan. ${ }^{3}$ Institute of Agriculture Sciences, \\ University of Punjab, Lahore, Pakistan.
}

\section{Authors' contributions}

SJ, UAA designed and wrote the manuscript.SK, MQ, MJS and NA helped me in manuscript writing. All authors read and approved the final manuscript.

Authors' information

Shah Jahan (PhD Molecular Biology), Usman Ali Ashfaq (PhD Molecular Biology),

Saba Khaliq (PhD Molecular Biology), Muhammad Qasim (PhD Molecular Biology)

Javed Saleem (PhD Molecular Biology), Nadeem Afzal (MSc Immunology)

\section{Competing interests}

All authors have no kind of institutional or financial competing interests.

Received: 14 December 2011 Accepted: 30 January 2012

Published: 30 January 2012

\section{References}

1. Hoofnagle $\mathrm{JH}$ : Course and outcome of hepatitis C. Hepatology 2002, 36: S21-29.

2. Alter MJ: Epidemiology of hepatitis C. Hepatology 1997, 26:62S-65S

3. Giannini C, Brechot C: Hepatitis C virus biology. Cell Death Differ 2003, 10(Suppl 1):S27-38.

4. Raja NS, Janjua KA: Epidemiology of hepatitis $C$ virus infection in Pakistan. J Microbiol Immunol Infect 2008, 41:4-8.

5. Khan UR, Janjua NZ, Akhtar S, Hatcher J: Case-control study of risk factors associated with hepatitis $C$ virus infection among pregnant women in hospitals of Karachi-Pakistan. Trop Med Int Health 2008, 13:754-761.

6. Idrees M, Rafique S, Rehman I, Akbar H, Yousaf MZ, Butt S, Awan Z, Manzoor S, Akram M, Aftab M, et al: Hepatitis C virus genotype 3a infection and hepatocellular carcinoma: Pakistan experience. World J Gastroenterol 2009, 15:5080-5085.
7. Raza SA, Clifford GM, Franceschi S: Worldwide variation in the relative importance of hepatitis $B$ and hepatitis $C$ viruses in hepatocellular carcinoma: a systematic review. Br J Cancer 2007, 96:1127-1134.

8. Lin C, Lindenbach BD, Pragai BM, McCourt DW, Rice CM: Processing in the hepatitis C virus E2-NS2 region: identification of p7 and two distinct E2specific products with different C termini. J Virol 1994, 68:5063-5073.

9. Reed $K E$, Rice $C M$ : Overview of hepatitis $C$ virus genome structure, polyprotein processing, and protein properties. Curr Top Microbiol Immunol 2000, 242:55-84.

10. Moriya K, Nakagawa K, Santa T, Shintani Y, Fujie H, Miyoshi H, Tsutsumi T, Miyazawa $T$, Ishibashi $K$, Horie $T$, et al: Oxidative stress in the absence of inflammation in a mouse model for hepatitis $C$ virus-associated hepatocarcinogenesis. Cancer Res 2001, 61:4365-4370.

11. Liu M, Ding H, Zhao P, Qin ZL, Gao J, Cao MM, Luan J, Wu WB, Qi ZT: RNA interference effectively inhibits mRNA accumulation and protein expression of hepatitis $C$ virus core and E2 genes in human cells. Biosci Biotechnol Biochem 2006, 70:2049-2055.

12. Pavlovic D, Neville DC, Argaud O, Blumberg B, Dwek RA, Fischer WB, Zitzmann N: The hepatitis $C$ virus $p 7$ protein forms an ion channel that is inhibited by long-alkyl-chain iminosugar derivatives. Proc Natl Acad Sci USA 2003, 100:6104-6108.

13. Walker MA: Hepatitis C virus: an overview of current approaches and progress. Drug Discov Today 1999, 4:518-529.

14. Bartenschlager R: Hepatitis C virus molecular clones: from CDNA to infectious virus particles in cell culture. Curr Opin Microbiol 2006, 9:416-422

15. Idrees $M$, Riazuddin S: Frequency distribution of hepatitis $C$ virus genotypes in different geographical regions of Pakistan and their possible routes of transmission. BMC Infect Dis 2008, 8:69.

16. Rubbia-Brandt L, Quadri R, Abid K, Giostra E, Male PJ, Mentha G, Spahr L, Zarski JP, Borisch B, Hadengue A, Negro F: Hepatocyte steatosis is a cytopathic effect of hepatitis C virus genotype 3. J Hepatol 2000, 33:106-115.

17. Koike K, Moriya K: Metabolic aspects of hepatitis $C$ viral infection: steatohepatitis resembling but distinct from NASH. J Gastroenterol 2005, 40:329-336.

18. Farinati F, Cardin R, De Maria N, Della Libera G, Marafin C, Lecis E, Burra P, Floreani A, Cecchetto A, Naccarato R: Iron storage, lipid peroxidation and glutathione turnover in chronic anti-HCV positive hepatitis. $J$ Hepatol 1995, 22:449-456.

19. Vidali M, Tripodi MF, Ivaldi A, Zampino R, Occhino G, Restivo L, Sutti S, Marrone A, Ruggiero G, Albano E, Adinolfi LE: Interplay between oxidative stress and hepatic steatosis in the progression of chronic hepatitis $C$. J Hepatol 2008, 48:399-406.

20. Penin F, Dubuisson J, Rey FA, Moradpour D, Pawlotsky JM: Structural biology of hepatitis C virus. Hepatology 2004, 39:5-19.

21. Moriya K, Fujie $H$, Shintani $Y$, Yotsuyanagi $H$, Tsutsumi T, Ishibashi $K$, Matsuura Y, Kimura S, Miyamura T, Koike K: The core protein of hepatitis C virus induces hepatocellular carcinoma in transgenic mice. Nat Med 1998, 4:1065-1067.

22. Nunez O, Fernandez-Martinez A, Majano PL, Apolinario A, GomezGonzalo M, Benedicto I, Lopez-Cabrera M, Bosca L, Clemente G, GarciaMonzon C, Martin-Sanz P: Increased intrahepatic cyclooxygenase 2, matrix metalloproteinase 2, and matrix metalloproteinase 9 expression is associated with progressive liver disease in chronic hepatitis $C$ virus infection: role of viral core and NS5A proteins. Gut 2004, 53:1665-1672.

23. Okuda M, Li K, Beard MR, Showalter LA, Scholle F, Lemon SM, Weinman SA: Mitochondrial injury, oxidative stress, and antioxidant gene expression are induced by hepatitis C virus core protein. Gastroenterology 2002, 122:366-375.

24. Chiarugi V, Magnelli L, Gallo O: Cox-2, iNOS and p53 as play-makers of tumor angiogenesis (review). Int J Mol Med 1998, 2:715-719.

25. Rahman MA, Dhar DK, Yamaguchi E, Maruyama S, Sato T, Hayashi H, Ono T, Yamanoi A, Kohno H, Nagasue $\mathrm{N}$ : Coexpression of inducible nitric oxide synthase and COX-2 in hepatocellular carcinoma and surrounding liver: possible involvement of COX-2 in the angiogenesis of hepatitis $C$ viruspositive cases. Clin Cancer Res 2001, 7:1325-1332.

26. Cheng AS, Chan HL, To KF, Leung WK, Chan KK, Liew CT, Sung J J: Cyclooxygenase-2 pathway correlates with vascular endothelial growth factor expression and tumor angiogenesis in hepatitis B virus-associated hepatocellular carcinoma. Int J Oncol 2004, 24:853-860. 
27. Tang TC, Poon RT, Lau CP, Xie D, Fan ST: Tumor cyclooxygenase-2 levels correlate with tumor invasiveness in human hepatocellular carcinoma. World J Gastroenterol 2005, 11:1896-1902.

28. Leng J, Han C, Demetris AJ, Michalopoulos GK, Wu T: Cyclooxygenase-2 promotes hepatocellular carcinoma cell growth through Akt activation: evidence for Akt inhibition in celecoxib-induced apoptosis. Hepatology 2003, 38:756-768.

29. Vivanco I, Sawyers CL: The phosphatidylinositol 3-Kinase AKT pathway in human cancer. Nat Rev Cancer 2002, 2:489-501.

30. Testa JR, Bellacosa A: AKT plays a central role in tumorigenesis. Proc Nat Acad Sci USA 2001, 98:10983-10985.

31. Assifi MM, Suchankova G, Constant S, Prentki M, Saha AK, Ruderman NB: AMP-activated protein kinase and coordination of hepatic fatty acid metabolism of starved/carbohydrate-refed rats. Am J Physiol Endocrinol Metab 2005, 289:E794-800.

32. Waris G, Felmlee DJ, Negro F, Siddiqui A: Hepatitis C virus induces proteolytic cleavage of sterol regulatory element binding proteins and stimulates their phosphorylation via oxidative stress. J Virol 2007, 81:8122-8130.

33. Shimano H, Horton JD, Shimomura I, Hammer RE, Brown MS, Goldstein JL: Isoform 1c of sterol regulatory element binding protein is less active than isoform 1a in livers of transgenic mice and in cultured cells. J Clin Invest 1997, 99:846-854.

34. Leone TC, Weinheimer CJ, Kelly DP: A critical role for the peroxisome proliferator-activated receptor alpha (PPARalpha) in the cellular fasting response: the PPARalpha-null mouse as a model of fatty acid oxidation disorders. Proc Natl Acad Sci USA 1999, 96:7473-7478.

35. Kersten S, Seydoux J, Peters JM, Gonzalez FJ, Desvergne B, Wahli W: Peroxisome proliferator-activated receptor alpha mediates the adaptive response to fasting. J Clin Invest 1999, 103:1489-1498.

36. Pianko S, Patella S, Ostapowicz G, Desmond P, Sievert W: Fas-mediated hepatocyte apoptosis is increased by hepatitis $C$ virus infection and alcohol consumption, and may be associated with hepatic fibrosis: mechanisms of liver cell injury in chronic hepatitis $C$ virus infection. Viral Hepat 2001, 8:406-413.

37. Cocquerel L, Wychowski C, Minner F, Penin F, Dubuisson J: Charged residues in the transmembrane domains of hepatitis $C$ virus glycoproteins play a major role in the processing, subcellular localization, and assembly of these envelope proteins. J Virol 2000, 74:3623-3633.

38. Tardif KD, Waris G, Siddiqui A: Hepatitis C virus, ER stress, and oxidative stress. Trends Microbiol 2005, 13:159-163.

39. Bureau C, Bernad J, Chaouche N, Orfila C, Beraud M, Gonindard C, Alric L, Vinel JP, Pipy B: Nonstructural 3 protein of hepatitis $C$ virus triggers an oxidative burst in human monocytes via activation of NADPH oxidase. $J$ Biol Chem 2001, 276:23077-23083.

40. Mahmood S, Yamada G, Niiyama G, Kawanaka M, Togawa K, Sho M, Ito T, Sasagawa T, Okita M, Nakamura H, Yodoi J: Effect of vitamin E on serum aminotransferase and thioredoxin levels in patients with viral hepatitis C. Free Radic Res 2003, 37:781-785.

41. Shimoda R, Nagashima M, Sakamoto M, Yamaguchi N, Hirohashi S, Yokota J, Kasai H: Increased formation of oxidative DNA damage, 8hydroxydeoxyguanosine, in human livers with chronic hepatitis. Cancer Res 1994, 54:3171-3172.

42. Lerat $H$, Honda M, Beard MR, Loesch K, Sun J, Yang Y, Okuda M, Gosert R, Xiao SY, Weinman SA, Lemon SM: Steatosis and liver cancer in transgenic mice expressing the structural and nonstructural proteins of hepatitis $C$ virus. Gastroenterology 2002, 122:352-365.

43. Suzuki R, Suzuki T, Ishii K, Matsuura $Y$, Miyamura T: Processing and functions of Hepatitis C virus proteins. Intervirology 1999, 42:145-152

44. Shigenaga MK, Hagen TM, Ames BN: Oxidative damage and mitochondrial decay in aging. Proc Natl Acad Sci USA 1994, 91:10771-10778.

45. Lee SH, Kim YK, Kim CS, Seol SK, Kim J, Cho S, Song YL, Bartenschlager R, Jang SK: E2 of hepatitis C virus inhibits apoptosis. J Immunol 2005 175:8226-8235

46. Schwarz KB: Oxidative stress during viral infection: a review. Free Radic Biol Med 1996, 21:641-649.

47. Majano PL, Garcia-Monzon C, Lopez-Cabrera M, Lara-Pezzi E, FernandezRuiz E, Garcia-Iglesias C, Borque MJ, Moreno-Otero R: Inducible nitric oxide synthase expression in chronic viral hepatitis. Evidence for a virusinduced gene upregulation. J Clin Invest 1998, 101:1343-1352.

48. Mihm S, Fayyazi A, Hartmann H, Ramadori G: Analysis of histopathological manifestations of chronic hepatitis $C$ virus infection with respect to virus genotype. Hepatology 1997, 25:735-739.

49. Garcia-Monzon C, Majano PL, Zubia I, Sanz P, Apolinario A, Moreno-Otero R: Intrahepatic accumulation of nitrotyrosine in chronic viral hepatitis is associated with histological severity of liver disease. J Hepatol 2000, 32:331-338.

50. Ahn B, Han BS, Kim DJ, Ohshima H: Immunohistochemical localization of inducible nitric oxide synthase and 3-nitrotyrosine in rat liver tumors induced by N-nitrosodiethylamine. Carcinogenesis 1999, 20:1337-1344.

51. Jaiswal M, LaRusso NF, Shapiro RA, Billiar TR, Gores GJ: Nitric oxidemediated inhibition of DNA repair potentiates oxidative DNA damage in cholangiocytes. Gastroenterology 2001, 120:190-199.

52. Smith WL, Langenbach R: Why there are two cyclooxygenase isozymes. J Clin Invest 2001, 107:1491-1495

53. Hla T, Neilson K: Human cyclooxygenase-2 cDNA. Proc Natl Acad Sci USA 1992, 89:7384-7388.

54. Jones DA, Carlton DP, Mclntyre TM, Zimmerman GA, Prescott SM: Molecular cloning of human prostaglandin endoperoxide synthase type II and demonstration of expression in response to cytokines. $J$ Biol Chem 1993, 268:9049-9054.

55. Koga H, Sakisaka M, Ohishi T, Kawaquchi E, Taniquchi K, Sasatomi M, Harada T, Kusaba M, Tanaka R, Kimura Y, et al: Expression of cyclooxygenase- 2 in human hepatocellular carcinoma: relevance to tumor dedifferentiation. Hepatology 1996, 29:688-696.

56. Rahman MA, Kohno H, Nagasue N: COX-2-a target for preventing hepatic carcinoma? Expert Opin Ther Targets 2002, 6:483-490.

57. Han C, Michalopoulos GK, Wu T: Prostaglandin E2 receptor EP1 transactivates EGFR/MET receptor tyrosine kinases and enhances invasiveness in human hepatocellular carcinoma cells. J Cell Physiol 2006, 207:261-270

58. Gallo O, Franchi A, Magnelli L, Sardi I, Vannacci A, Boddi V, Chiarugi V, Masini E: Cyclooxygenase-2 pathway correlates with VEGF expression in head and neck cancer. Implications for tumor angiogenesis and metastasis. Neoplasia 2001, 3:53-61.

59. Amano H, Haysahi I, Yoshida S, Yoshimura H, Majima M: Cyclooxygenase-2 and adenylate cyclase/protein kinase A signaling pathway enhances angiogenesis through induction of vascular endothelial growth factor in rat sponge implants. Hum Cell 2002, 15:13-24.

60. Wu G, Luo J, Rana JS, Laham R, Sellke FW, Li J: Involvement of COX-2 in VEGF-induced angiogenesis via P38 and JNK pathways in vascular endothelial cells. Cardiovasc Res 2006, 69:512-519.

61. Zhou G, Myers R, Li Y, Chen Y, Shen X, Fenyk-Melody J, Wu M, Ventre J, Doebber T, Fuji N, et al: Role of AMP-activated protein kinase in mechanism of metformin action. J Clin Invest 2001, 108:1167-1174.

62. Tsujii M, DuBois RN: Alterations in cellular adhesion and apoptosis in epithelial cells overexpressing prostaglandin endoperoxide synthase 2. Cell 1995, 83:493-501.

63. Dennis EA: The growing phospholipase $A 2$ superfamily of signal transduction enzymes. Trends Biochem Sci 1997, 22:1-2.

64. Balsinde J, Balboa MA, Insel PA, Dennis EA: Regulation and inhibition of phospholipase A2. Annu Rev Pharmacol Toxicol 1999, 39:175-189.

65. Mayoral R, Fernandez-Martinez A, Bosca L, Martin-Sanz P: Prostaglandin E2 promotes migration and adhesion in hepatocellular carcinoma cells. Carcinogenesis 2005, 26:753-761.

66. Abiru S, Nakao K, Ichikawa T, Migita K, Shigeno M, Sakamoto M, Ishikawa H, Hamasaki K, Nakata K, Eguchi K: Aspirin and NS-398 inhibit hepatocyte growth factor-induced invasiveness of human hepatoma cells. Hepatology 2002, 35:1117-1124.

67. Cianchi F, Cortesini C, Bechi P, Fantappie O, Messerini L, Vannacci A, Sardi I, Baroni G, Boddi V, Mazzanti R, Masini E: Up-regulation of cyclooxygenase 2 gene expression correlates with tumor angiogenesis in human colorectal cancer. Gastroenterology 2001, 121:1339-1347.

68. Hope RG, Murphy DJ, McLauchlan J: The domains required to direct core proteins of hepatitis $C$ virus and GB virus-B to lipid droplets share common features with plant oleosin proteins. J Biol Chem 2002, 277:4261-4270.

69. Emerit I, Serejo F, Filipe P, Alaoui Youssefi A, Fernandes A, Costa A, Freitas J, Ramalho F, Baptista A, Carneiro de Moura M: Clastogenic factors as 
biomarkers of oxidative stress in chronic hepatitis C. Digestion 2000, 62:200-207.

70. Abid K, Pazienza V, de Gottardi A, Rubbia-Brandt L, Conne B, Pugnale P, Rossi C, Mangia A, Negro F: An in vitro model of hepatitis $C$ virus genotype 3a-associated triglycerides accumulation. J Hepatol 2005, 42:744-751.

71. Fartoux L, Poujol-Robert A, Guechot J, Wendum D, Poupon R, Serfaty L: Insulin resistance is a cause of steatosis and fibrosis progression in chronic hepatitis C. Gut 2005, 54:1003-1008.

72. Pekow JR, Bhan AK, Zheng H, Chung RT: Hepatic steatosis is associated with increased frequency of hepatocellular carcinoma in patients with hepatitis C-related cirrhosis. Cancer 2007, 109:2490-2496.

73. Bieche I, Asselah T, Laurendeau I, Vidaud D, Degot C, Paradis V, Bedossa P, Valla DC, Marcellin P, Vidaud M: Molecular profiling of early stage liver fibrosis in patients with chronic hepatitis C virus infection. Virology 2005, 332:130-144.

74. Westin J, Nordlinder H, Lagging M, Norkrans G, Wejstal R: Steatosis accelerates fibrosis development over time in hepatitis $C$ virus genotype 3 infected patients. J Hepatol 2002, 37:837-842.

75. Rubbia-Brandt L, Fabris P, Paganin S, Leandro G, Male PJ, Giostra E, Carlotto A, Bozzola L, Smedile A, Negro F: Steatosis affects chronic hepatitis C progression in a genotype specific way. Gut 2004, 53:406-412.

76. Patton HM, Patel K, Behling C, Bylund D, Blatt LM, Vallee M, Heaton S, Conrad A, Pockros PJ, McHutchison JG: The impact of steatosis on disease progression and early and sustained treatment response in chronic hepatitis C patients. J Hepatol 2004, 40:484-490.

77. Hezode C, Roudot-Thoraval F, Zafrani ES, Dhumeaux D, Pawlotsky JM: Different mechanisms of steatosis in hepatitis C virus genotypes 1 and 3 infections. J Viral Hepat 2004, 11:455-458.

78. Halse R, Pearson SL, McCormack JG, Yeaman SJ, Taylor R: Effects of tumor necrosis factor-alpha on insulin action in cultured human muscle cells. Diabetes 2001, 50:1102-1109.

79. Uysal KT, Wiesbrock SM, Marino MW, Hotamisligil GS: Protection from obesity-induced insulin resistance in mice lacking TNF-alpha function. Nature 1997, 389:610-614.

doi:10.1186/1750-9378-7-2

Cite this article as: Jahan et al: Hepatitis C virus to hepatocellular carcinoma. Infectious Agents and Cancer 2012 7:2.

\section{Submit your next manuscript to BioMed Central and take full advantage of:}

- Convenient online submission

- Thorough peer review

- No space constraints or color figure charges

- Immediate publication on acceptance

- Inclusion in PubMed, CAS, Scopus and Google Scholar

- Research which is freely available for redistribution

Submit your manuscript at www.biomedcentral.com/submit
Ciomed Central 